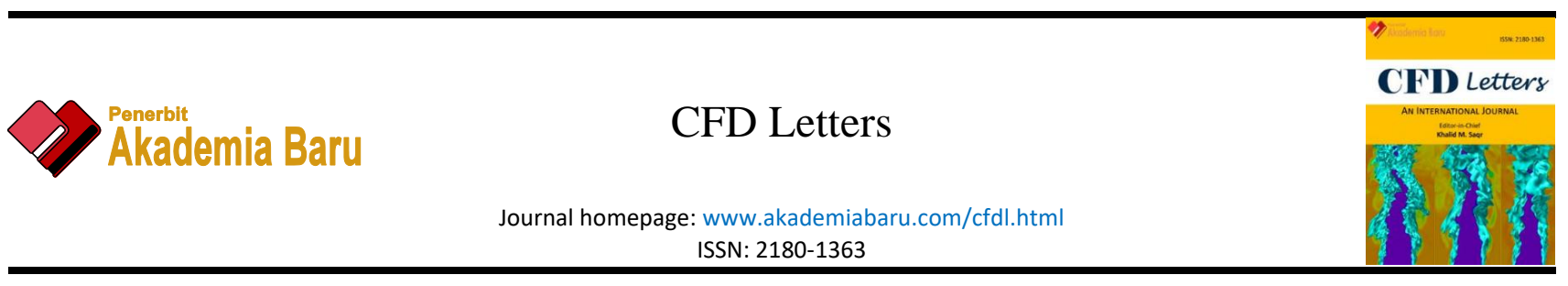

\title{
Simulation Study on the Performance of a Counter-rotating Savonius Vertical Axis Wind Turbine
}

\author{
Djamal Hissein Didane ${ }^{1,{ }^{*}}$, Muhammad Amir Zafran Saipul Anuar ${ }^{1}$, Mohd Faizal Mohideen Batcha ${ }^{1}$, \\ Kamil Abdullah ${ }^{1}$, Mas Fawzi Mohd Ali $^{1}$, Akmal Nizam Mohammed ${ }^{1}$
}
1 Department of Energy and Thermofluid Engineering, Faculty of Mechanical and Manufacturing Engineering, Universiti Tun Hussein Onn Malaysia, 86400 Parit Raja, Batu Pahat, Johor, Malaysia

\section{ARTICLE INFO ABSTRACT}

\section{Article history:}

Received 19 February 2020

Received in revised form 16 April 2020

Accepted 21 April 2020

Available online 28 April 2020

\begin{abstract}
Wind power is an energy source that is becoming an alternative to burning fossil fuels that may harm the environment during operations due to the emission of harmful gases. In this study, simulation and performance investigations of a counter-rotating vertical axis wind turbine (VAWT) based on the Savonius S-type rotor have been analysed through a computational simulation approach. The foremost motive of this study is to widen the operating wind speed range of the counter-rotating concept in a VAWT while enhancing the conversion efficiency of a single-rotor VAWT system. The 3D simulations were performed based on the K-omega shear stress transport (SST) turbulence model. The results have shown that the counter-rotating model possesses better performance characteristics in terms of torque, power and their corresponding coefficients compared to a single-rotor design of a wind turbine. A maximum output of more than two times was obtained from the new CRWT system compared to that of a single-rotor wind turbine (SRWT). Moreover, the output of the top rotor was higher than the bottom rotor due to the increased higher rotational speed of the top rotor.
\end{abstract}

Keywords:

CFD simulation; Savonius rotor; vertical axis wind turbine (VAWT); counterrotating wind turbine; low-speed wind

\section{Introduction}

Wind power is an energy source that has the characteristics of a clean, free and readily available type of energy. It is used as an alternative to burning fossil fuels that may harm the environment during operations due to the emission of harmful gases [1-3]. Recent studies have shown that wind energy is currently the second fastest growing source of electricity generation today as it is renewable, free and eco-friendly [4]. Thus, wind turbine power has an excellent potential to be developed all over the globe in the near future as the stream of wind flows continuously around us to make it a better choice compared to other forms of energy generation [5-7]. Wind turbines are found to be a strategic solution for large scale applications such as national grids and commercial

\footnotetext{
* Corresponding author.

E-mail address: djamal@uthm.edu.my (Djamal Hissein Didane)
} 
scale power productions. The most extensive system in modern wind turbines can generate about 2 megawatts of power, which is enough to power over 2000 houses.

There are a few types of wind turbine designs exist. They divided into two based on the axis in which the rotor spins such as the horizontal-axis wind turbine (HAWT) and vertical-axis wind turbine (VAWT). HAWT is dominating the market and more preferred by the investors. As its name denotes, the axis of the rotor's rotation of HAWT is parallel to the ground and the wind stream [8]. The working principle of both VAWTs and HAWTs is similar. As the air passes through the blades, the wind will rotate the rotor and spun the wind turbine into the generator through rotational momentum. There are typically two or three blades with a vertically operating main rotor shaft, but if more blades are added, the efficiency is higher as more wind energy is received [9]. The rotor shaft is arranged in a vertical pattern and it is easier to maintain compared to a HAWT. There are two main designs of VAWT; Darrius wind turbine and Savonius wind turbine. However, only recently, the application of the counter-rotation concept on VAWTs took place, as shown in Figure 1.

The Savonius-type wind turbines or also known as S-rotor was originally invented by Sigurd J. Savonius, a Finnish engineer in 1931 [10]. This type of wind turbine which is classified as a VAWT, can operate independently on the direction of the wind and self-starts at a lower wind speed compared to HAWT. Savonius once said that the best of his rotors had a maximum efficiency of as high as $31 \%$ [11]. Over the years, the Savonius turbine had suffered from a low-efficiency performance. Extensive theoretical and experimental studies have been reported to create a new design and able to make a significant improvement at the level of power coefficient compared to conventional Savonius rotors successfully. However, its conversion efficiency is still lower than the HAWT [12].

The simple Savonius rotor device with a half-cylindrical parts that are attached to the opposite sides of a vertical shaft operates based on the principle of a drag force. Thus, it cannot rotate faster than the wind speed, which means that the tip-speed ratio is equal to 1 or smaller. It works due to the difference of exerted forces on each blade. The blade is forced to rotate around its central vertical shaft when the concave part to the wind direction caught the air wind. The convex part hits the air wind and causes the blade to be deflected sideways around the shaft. The blades curvature has less drag force when moving against the wind than the blades moving with the wind [10]. Thus, the rotor will be forced to rotate as the concave blades have more drag force than the other half cylinder.

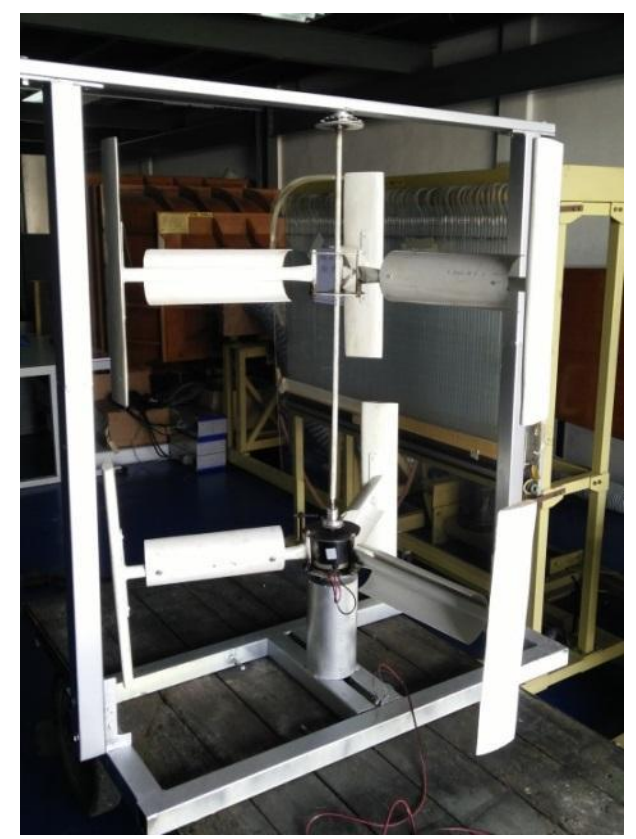

Fig. 1. Counter-rotating VAWT [13] 
On the other hand, the other type of operating mechanism of a wind turbine is the concept of counter-rotating wind turbine (CRWT). It is found in both HAWT and VAWT, although it has just been introduced to VAWTs recently [13-16]. It is a system of dual rotors which rotate in opposite directions to one another. One of the rotors rotates in a clockwise direction and the other in a counter-clockwise direction [17]. In the last few years, the investigation of the CRWT has been thoroughly approached both numerically and experimentally. It was indicated that the performance of a single-rotor wind turbine (SRWT) had improved significantly with the efficiency of about $43 \%$ and $40 \%$ in terms of torque and power, respectively [13-15]. However, the only drawback was that the system was not able to operate at wind speeds below $5 \mathrm{~m} / \mathrm{s}$. Motivated from this limitation and the potential of improvement that is expected from this concept, the present study is set out to improve the performance of VAWT with counter-rotating concept while using the Savonius S-type rotor. The Savonius S-type rotor is renowned for its inherent characteristics of operating at a lower wind speed compared to straight-bladed H-type rotor which was used in the previous studies of CRWT for a VAWT. Thus, this rotor is anticipated to widen the operating range of this concept while enhancing the performance of a SRWT with a vertical axis.

\section{Theoretical Formulation}

The aerodynamic quantity of a wind turbine such as power, torque and tip-speed ratio (TSR) is typically calculated while evaluating the performance of a wind turbine. Thus, in the present study, the experimental power out which is calculated from the mechanical torque is given as shown in Eq. (1) was sought thoroughly. Furthermore, the theoretical power and theoretical torque in the wind are given in Eq. (2) and Eq. (3), respectively.

$P_{e x}=T_{m} \omega$

where $T_{m}$ and $\omega$ are respectively the mechanical torque and rotational speed of the rotor.

$P_{T}=\frac{1}{2} \rho A V^{3}$

$T_{T}=\frac{1}{2} \rho_{a} V A^{2} R$

where $\rho$ is the density of air, $A$ is projected area on the rotor $(\mathrm{D} \times \mathrm{H}), V$ is the velocity of the wind and $R$ is the radius of the blade.

\section{Methodology}

\subsection{Geometry of The Model}

The Savonius rotor for the present study is designed with the radius of c-shape in $30 \mathrm{~cm}$ total radius. The combination of the three blades has been cut from their actual radius of $30 \mathrm{~cm}$ to $27 \mathrm{~cm}$, in order to allow $3 \mathrm{~cm}$ for the circular hub that connects all three blades. In total, six blades were developed. Both top and bottom rotors were designed based on the Savonius s-type rotor. All blade dimensions such as blade height $(H)$, thickness $(t)$ and diameter $(D)$ were identical to achieve optimum performance during the simulation process. Figure 2 shows the present counter-rotating model. The main features and details of the current design are given in Table 1 and Figure 3. 
Table 1

Main features

\begin{tabular}{ll}
\hline Feature & Detail \\
\hline Type of blade & S-type \\
Number of blades & 3 \\
Radius, R & $30 \mathrm{~cm}$ \\
Height, $\mathrm{H}$ & $12 \mathrm{~cm}$ \\
Thickness, $\mathrm{t}$ & $0.5 \mathrm{~cm}$ \\
\hline
\end{tabular}

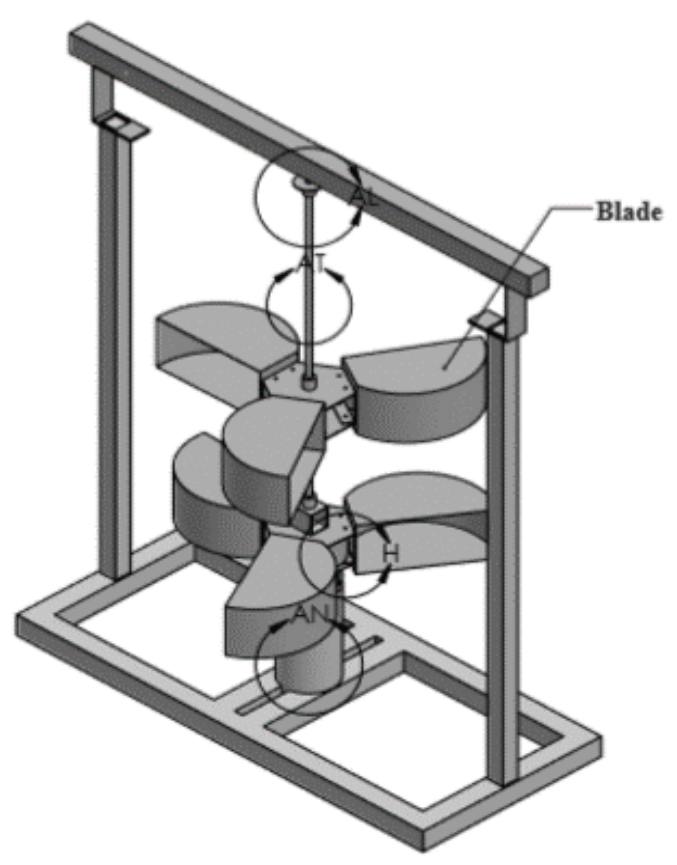

Fig. 2. CRWT rotor model layout

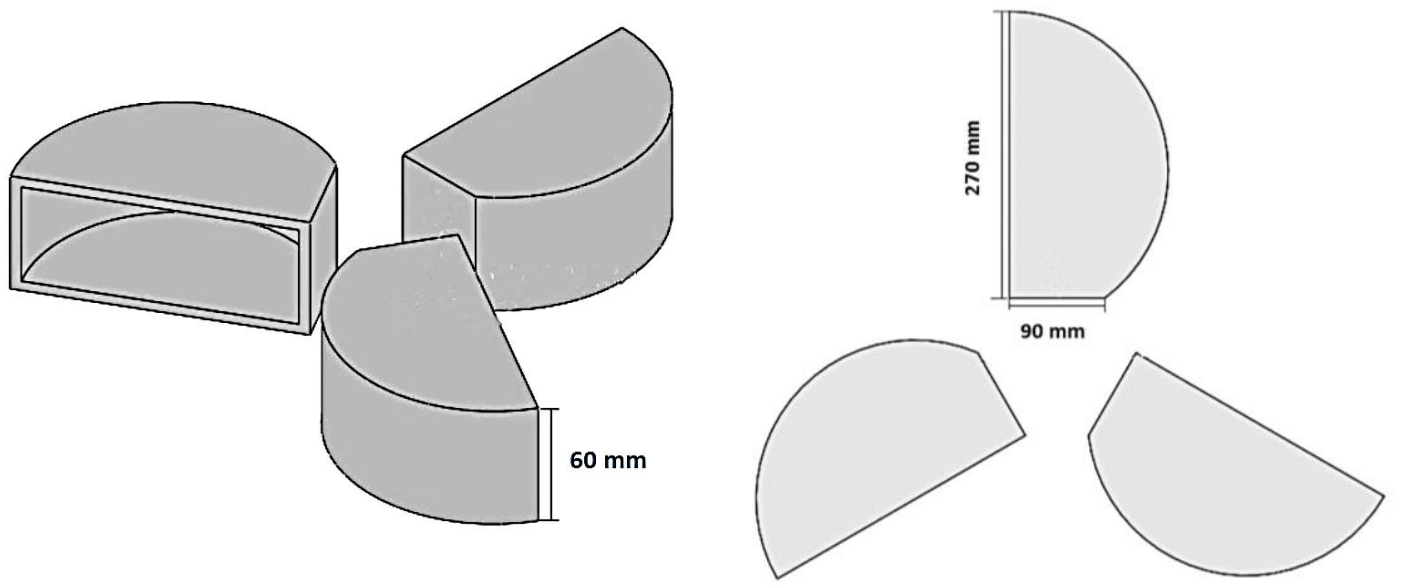

Fig. 3. Model dimensional details

\subsection{Computational Simulation}

The modelling software SolidWorks was used to develop and create the current CAD model, as shown in Figure 2. Only the blades were considered in the simulation as shown in Figure 3. The computational domain has been separated into two zones; fixed zone and rotating zone, as shown in Figure 4. The fixed zone refers to the calculation area of the simulation and the rotating circular 
zone shows the rotating domain where the two counter-rotating rotors are turning. Moreover, the rotating zones itself has been divided into two sub-zones. One for each rotor (top and bottom), since they rotate in different directions, as shown in Figure 4.

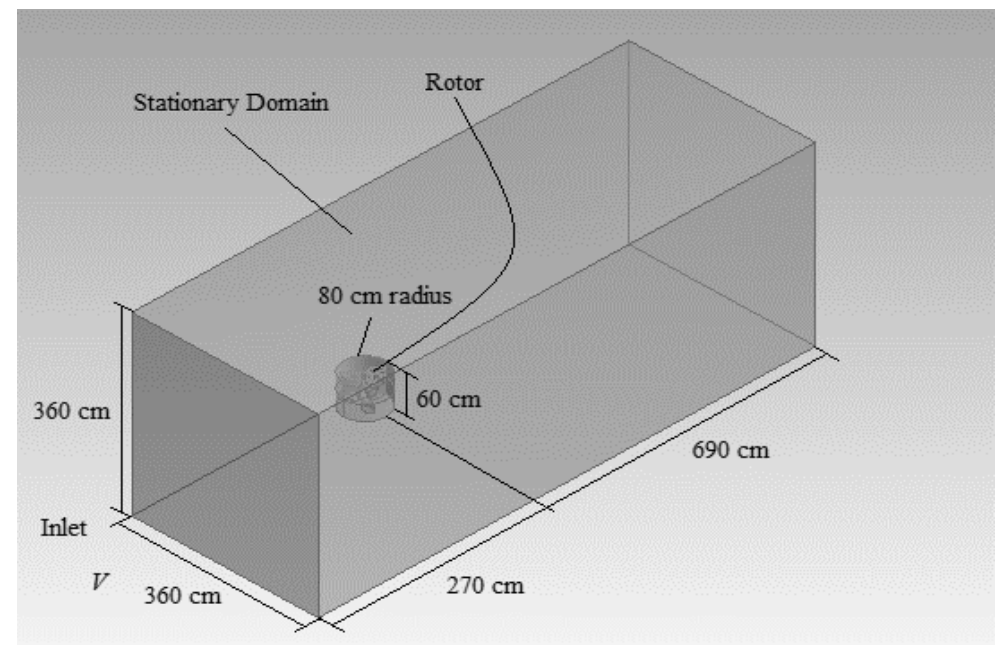

Fig. 4. Simulation domain

A uniform velocity inlet and pressure outlet boundary conditions were respectively assigned at the inlet and outlet regions of the model. Meanwhile, the blades, the top wall, bottom wall and lateral walls were assigned as non-slip wall boundary conditions. Non-conformal interface boundary conditions were assigned between the top and bottom domain and also between the rotating and fixed zones. The current model was meshed with structured mesh with a finer mesh near the blade walls as shown in Figure 5. The maximum skewness was maintained below 0.85 .

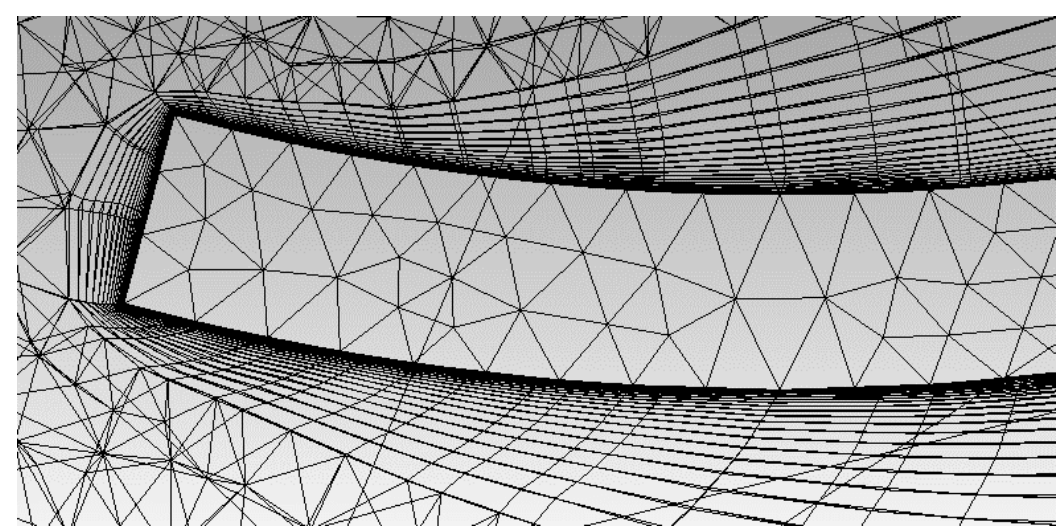

Fig. 5. Close view of the mesh on the blade edge

\subsection{Flow Solver}

The function of flow solver is to solve the governing flow equations while ANSYS FLUENT is to run the input data. The built-in application in ANSYS WORKBENCH named FLUENT 19.1 is used for the simulation of fluid flow in the current design. The incompressible unsteady Reynolds-averaged Navier-Stokes (RANS) equations were used to solve the flow problem. The turbulent viscosity model implemented was the k-omega shear stress transport (SST) model. The solution method has adopted the pressure-velocity coupling algorithm as the solution scheme for the simulation process. All input functions such as the wind speed range covered and the corresponding rotational speed are shown in Table 2. 
Table 2

\begin{tabular}{lll}
\multicolumn{3}{l}{ Input parameters } \\
\hline \multirow{2}{*}{ Wind speed (m/s) } & \multicolumn{2}{l}{ Rotational speed (RPM) } \\
\cline { 2 - 3 } & Top rotor & Bottom rotor \\
\hline 2 & 78 & 78 \\
3 & 88 & 12 \\
4 & 102 & 28 \\
5 & 115 & 50 \\
6 & 132 & 62 \\
7 & 141 & 68 \\
8 & 174 & 118 \\
9 & 176 & 120 \\
\hline
\end{tabular}

\section{Results}

The computational simulation process starts with a verification process of the settings of the current simulation analysis with past studies before embarking on the simulation. Thus, the Gridindependent test (GIT), is used as one of the verification processes for this study. Next, the study continued with a validation process of the current numerical results with a past experimental study.

\subsection{Grid-Independent Study (GIT)}

The GIT is performed while testing various mesh sizes. Table 3 shows the torque results of the current numerical results of CRWT model by using several sets of grid numbers of seven different mesh sizing for the adopted model at an operating wind of $2 \mathrm{~m} / \mathrm{s}$. From the results, it can be observed that the outputs from all different mesh sizes were close to the experimental study. Nevertheless, the results become grid-independent only after one million number of elements.

The numerical results of the torque tend to be more stable when the mesh size increases and the percentage of relative error also decreases to less than $10 \%$ starting at 626323 element size up to almost 6 million as shown in Table 3. However, the difference between 1.5 million and 5.9 million mesh size is less than $4 \%$, which means that the solution has become independent from the grid. Thus, this mesh size is selected for the simulation process in order to avoid the high computational cost.

\section{Table 3}

Grid independent test results

\begin{tabular}{lll}
\hline Velocity $(\mathrm{m} / \mathrm{s})$ & & 2 \\
\hline Size of Elements & No of Elements & Torque $(\mathrm{Nm})$ \\
\hline 0.2 & 624791 & 0.11038 \\
0.1 & 625501 & 0.11099 \\
0.05 & 625454 & 0.10975 \\
0.04 & 626323 & 0.11371 \\
0.025 & 665650 & 0.11381 \\
0.01 & 1532485 & 0.11976 \\
0.005 & 5865664 & 0.12051 \\
\hline
\end{tabular}

\subsection{Model Validation}

The validation process was conducted by comparing the output results of the current simulation study with the previous experimental study. The validation involved comparing the results of the 
torque output. Figure 6 shows the validation of the current simulation with a previous experimental study conducted by Kudam [18] of the torque output. The results from the present study are comparable with the previous experimental results. The relative error obtained is about $12 \%$, which gives more confidence in the present simulation settings to predict the desired results.

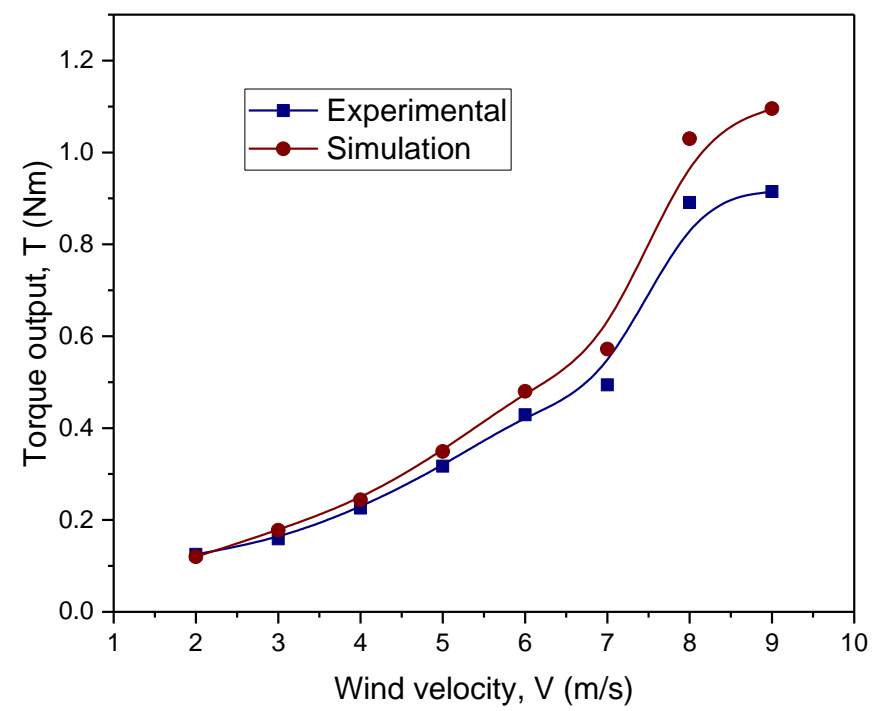

Fig. 6. Validation with previous study torque against wind speed

\subsection{Evaluations of Power Output}

The performance of the present counter-rotating model in terms of power output is presented in Figure 7. As shown in the figure, the simulation results show the potential and effectiveness of the counter-rotation concept applied in a Savonius VAWT. The model was tested from $2 \mathrm{~m} / \mathrm{s}$ up to $9 \mathrm{~m} / \mathrm{s}$ wind speed. It is observed that the power of the rotors varies significantly with wind speed. The power output of the CRWT model gradually increases as the wind speed increases.

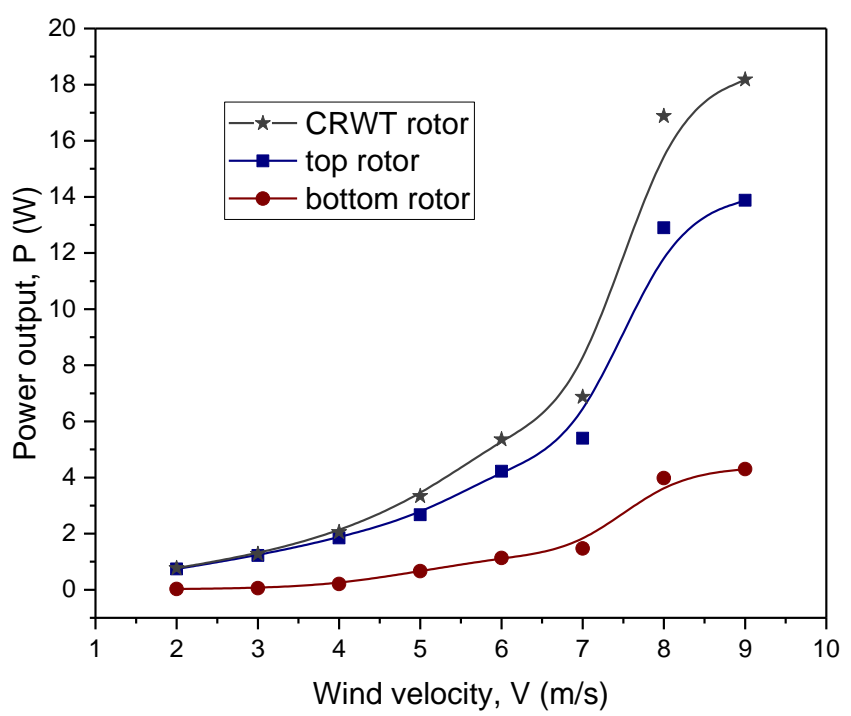

Fig. 7. Simulation power variation against wind speed

It was also clear that the existence of the top rotor caused a considerable impact on the quantity of power produced from the wind turbine which could not be achieved with a traditional single-rotor 
Savonius VAWT as shown in Figure 7. Moreover, given that the rotational speed of the top rotor was higher than the bottom rotor, the corresponding power output was also higher. It is also noted that comparing the top and bottom rotors, the amount generated from both rotors tend to increase and the difference becomes more evident as the upstream wind increases. The performance of this new design at this lower speed $(2 \mathrm{~m} / \mathrm{s})$ would be beneficial for wind energy conversion applications, especially in places that suffer from a low-speed wind.

\subsection{Evaluations of Torque Output}

In general, the strength of the wind speed significantly affects the performance of a wind turbine. In this section, the performance of the CRWT is evaluated in terms of torque output with a wind speed starting from $2 \mathrm{~m} / \mathrm{s}$ until $9 \mathrm{~m} / \mathrm{s}$ wind speed. The results of the current simulation study are illustrated in Figure 8. It is indicated that the average torque output has a steady increase with the increase of the wind velocity for both the upper rotor and lower rotor, as shown in Figure 8. Again, the top rotor shows more output compared to the bottom rotor due to the increased rotational speed of the top rotor. Thus, the combined output (CRWT) from the two rotors is more than two times on average compared to the single-rotor, which is quite significant.

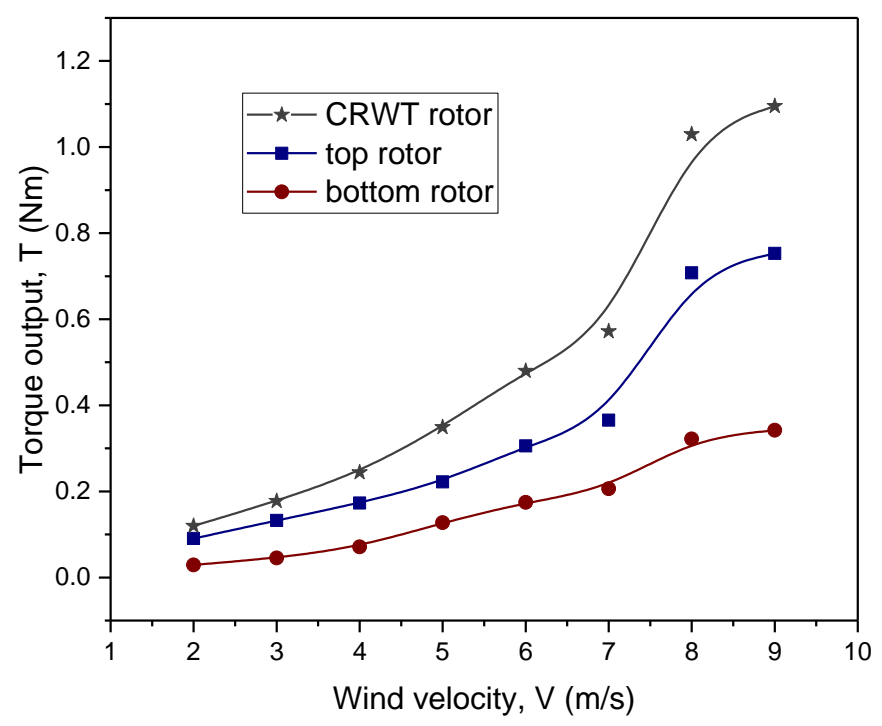

Fig. 8. Simulation of torque against wind speed

Furthermore, Figure 9 shows the velocity contours concerning upstream wind. It is observed that the velocity contour of the lower rotor is lower compared to the top rotor. This is due to the slower rotational speed of the bottom rotor. Moreover, it is also clear that the velocity distribution around the blades of the model was higher at the tip of the blades, while the lowest velocity is found at the centre of rotation.

The effect of pressure gradient becomes less evident at higher wind condition due to higher rotational speed. The explanation in this scenario is because the pressure gradient and the torque decrease at higher rotational speeds. The simulation results show that the pressure forces and viscosity forces on the surfaces of blades affected by torque variation, although the viscosity vectors cause only a small amount. 

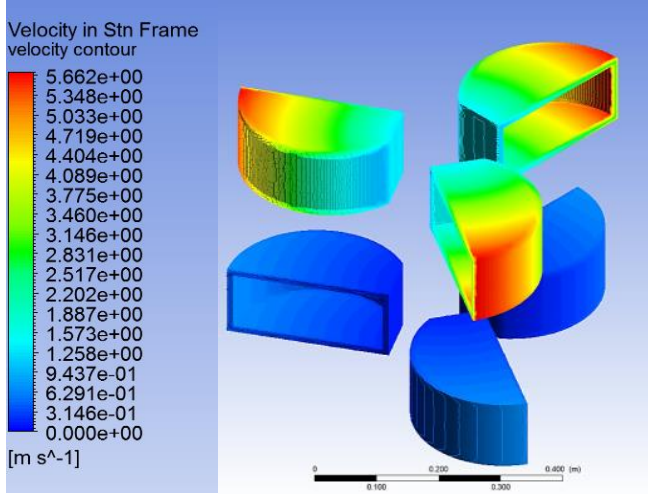

$2 \mathrm{~m} / \mathrm{s}$

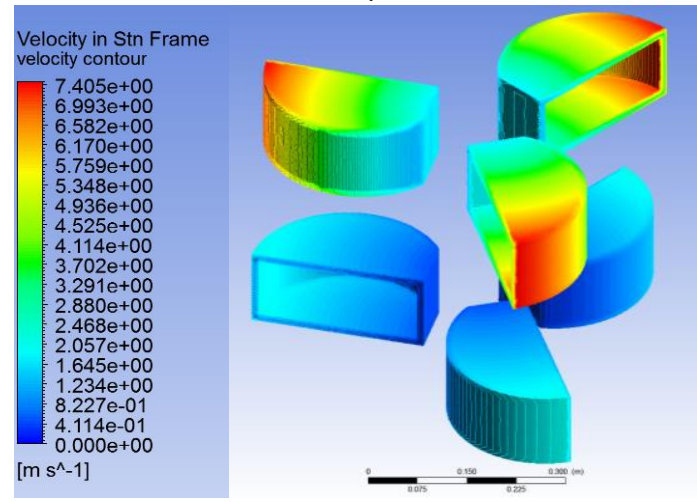

$4 \mathrm{~m} / \mathrm{s}$

\begin{tabular}{|c|}
\hline $\begin{array}{l}\text { Velocity in Stn Frame } \\
\text { velocity contour }\end{array}$ \\
\hline 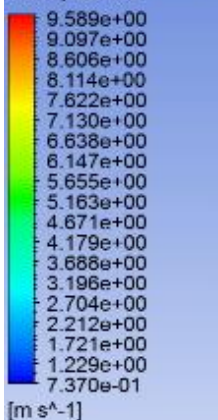 \\
\hline
\end{tabular}
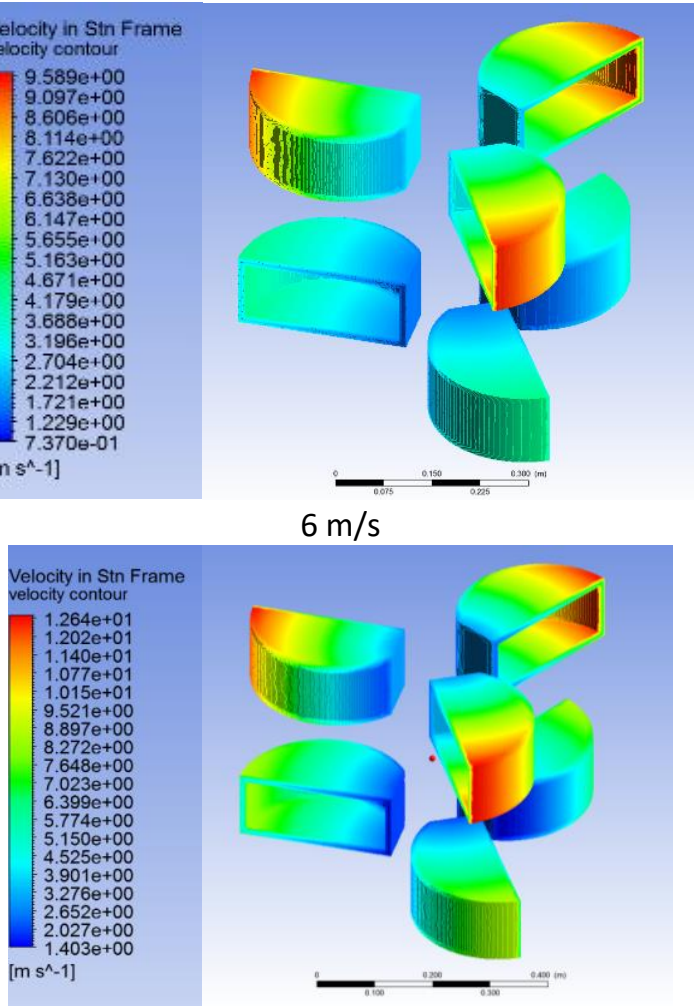

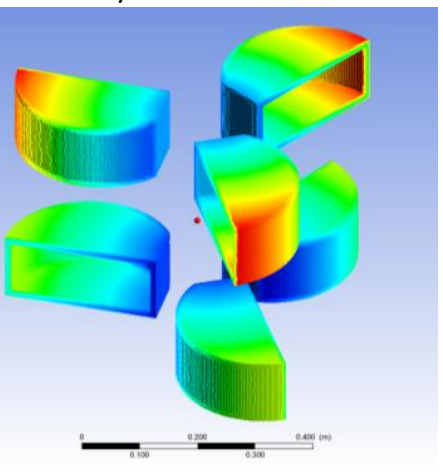

$8 \mathrm{~m} / \mathrm{s}$
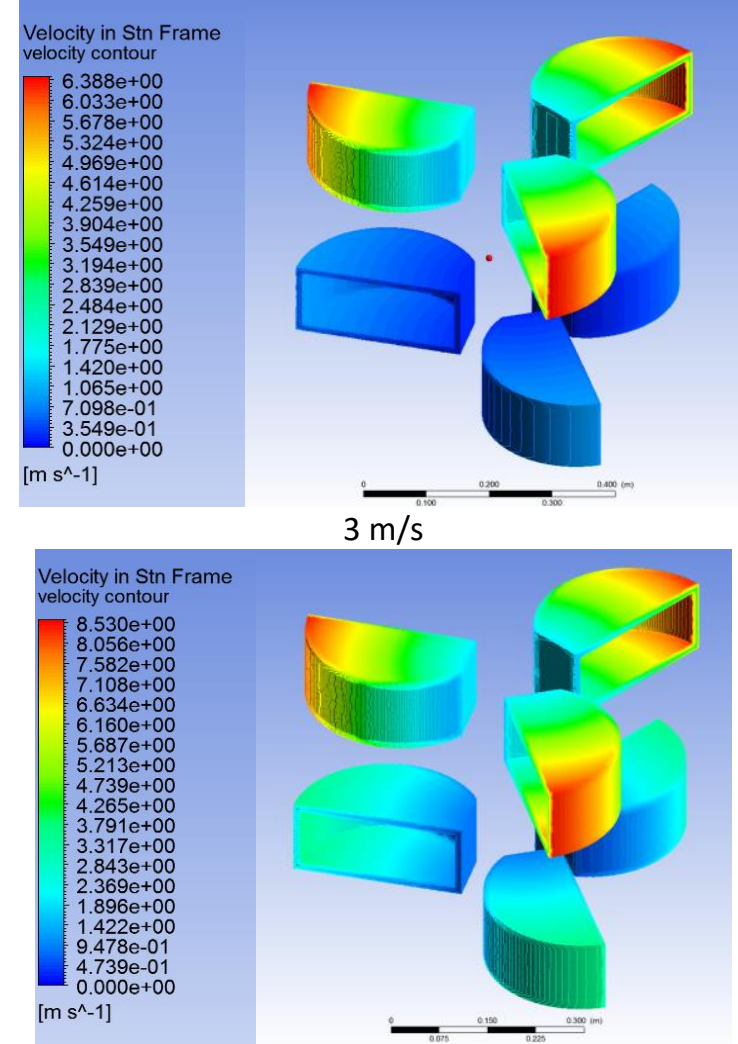

$5 \mathrm{~m} / \mathrm{s}$

\begin{tabular}{l} 
Velocity in Stn Frame \\
velocity contour \\
\begin{tabular}{|l}
$1.024 \mathrm{e}+01$ \\
$9.719 \mathrm{e}+00$ \\
$9.195 \mathrm{e}+00$ \\
$8.671 \mathrm{e}+00$ \\
$8.146 \mathrm{e}+00$ \\
$7.622 \mathrm{e}+00$ \\
$7.098 \mathrm{e}+00$ \\
$6.574 \mathrm{e}+00$ \\
$6.050 \mathrm{e}+00$ \\
$5.526 \mathrm{e}+00$ \\
$5.002 \mathrm{e}+00$ \\
$4.477 \mathrm{e}+00$ \\
$3.953 \mathrm{e}+00$ \\
$3.429 \mathrm{e}+00$ \\
$2.905 \mathrm{e}+00$ \\
$2.381 \mathrm{e}+00$ \\
$1.857 \mathrm{e}+00$ \\
$1.332 \mathrm{e}+00$ \\
$8.083 \mathrm{e}-01$
\end{tabular} \\
{$[\mathrm{~m}$} \\
$\left.\mathrm{s}^{\wedge}-1\right]$ \\
\hline
\end{tabular}
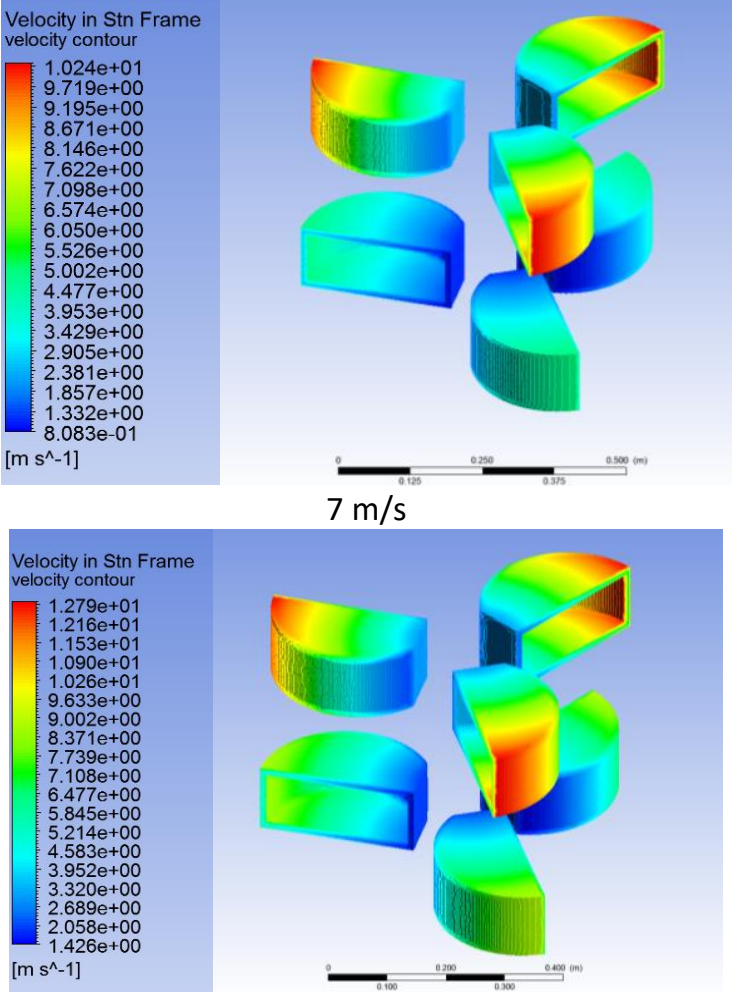

$7 \mathrm{~m} / \mathrm{s}$

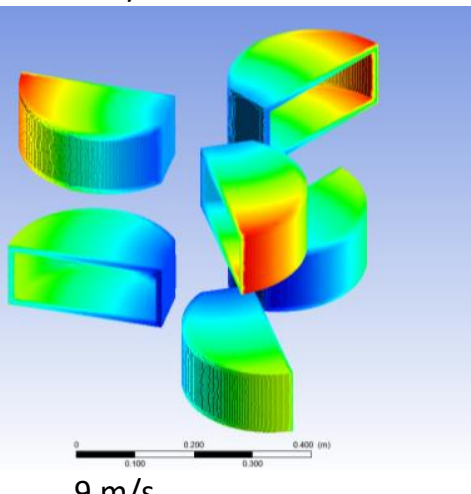

Fig. 9. Velocity contours for upstream wind 


\section{Conclusions}

In this study, simulations of the counter-rotating VAWT based on Savonius S-type rotor have been studied numerically. Both upper and lower rotors were identical in terms of dimension and shape. There were six blades in total (three blades for each rotor). The following conclusions could be drawn from this study

i. The counter-rotating model has shown better performance characteristics in terms of torque, power and their corresponding coefficients compared to a single rotor design of the wind turbine.

ii. The output of the top rotor was higher than the bottom rotor due to the increased higher rotational speed of the top rotor

iii. The aerodynamic characteristics such as torque and power have shown that the maximum output of the new CRWT system was higher than two times compared to that of a SRWT.

\section{Acknowledgement}

This research was funded by Universiti Tun Hussein Onn Malaysia under the research grant H126.

\section{References}

[1] Jamil, M., S. Parsa, and M. Majidi. "Wind power statistics and an evaluation of wind energy density." Renewable energy 6, no. 5-6 (1995): 623-628. https://doi.org/10.1016/0960-1481(95)00041-H

[2] Stout, Craig, Sheikh Islam, Alasdair White, Scott Arnott, Erald Kollovozi, Morven Shaw, Ghazi Droubi, Yashwant Sinha, and Benjamin Bird. "Efficiency improvement of vertical axis wind turbines with an upstream deflector." Energy procedia 118 (2017): 141-148. https://doi.org/10.1016/j.egypro.2017.07.032

[3] Didane, D. H., S. Mohd, Z. Subari, N. Rosly, M. A. Ghafir, and M. M. Masrom. "An aerodynamic performance analysis of a perforated wind turbine blade." In IOP Conference Series: Materials Science and Engineering, vol. 160, no. 1, p. 012039. IOP Publishing, 2016.

https://doi:10.1088/1757-899X/160/1/012039

[4] Dai, Kaoshan, Anthony Bergot, Chao Liang, Wei-Ning Xiang, and Zhenhua Huang. "Environmental issues associated with wind energy-A review." Renewable Energy 75 (2015): 911-921.

https://doi.org/10.1016/j.renene.2014.10.074

[5] Didane, Djamal Hissein, Abas Ab Wahab, Syariful Syafiq Shamsudin, Nurhayati Rosly, Mohd Fadhli Zulkafli, and Sofian Mohd. "Assessment of wind energy potential in the capital city of Chad, N'Djamena." In AIP Conference Proceedings, vol. 1831, no. 1, p. 020049. AIP Publishing LLC, 2017.

https://doi.org/10.1063/1.4981190

[6] Wang, Zhenyu, Yuchen Wang, and Mei Zhuang. "Improvement of the aerodynamic performance of vertical axis wind turbines with leading-edge serrations and helical blades using CFD and Taguchi method." Energy conversion and management 177 (2018): 107-121. https://doi.org/10.1016/i.enconman.2018.09.028

[7] Cho, Whang, Kooksun Lee, Ick Choy, and Juhoon Back. "Development and experimental verification of counterrotating dual rotor/dual generator wind turbine: Generating, yawing and furling." Renewable Energy 114 (2017): 644-654. https://doi.org/10.1016/j.renene.2017.06.083

[8] O'Brien, J. M., T. M. Young, D. C. O'Mahoney, and P. C. Griffin. "Horizontal axis wind turbine research: A review of commercial CFD, FE codes and experimental practices." Progress in Aerospace Sciences 92 (2017): 1-24. https://doi.org/10.1016/i.paerosci.2017.05.001

[9] Shah, Sahishnu R., Rakesh Kumar, Kaamran Raahemifar, and Alan S. Fung. "Design, modeling and economic performance of a vertical axis wind turbine." Energy Reports 4 (2018): 619-623.

https://doi.org/10.1016/j.egyr.2018.09.007

[10] Wenehenubun, Frederikus, Andy Saputra, and Hadi Sutanto. "An experimental study on the performance of Savonius wind turbines related with the number of blades." Energy procedia 68 (2015): 297-304. 
https://doi.org/10.1016/j.egypro.2015.03.259

[11] Zemamou, M., M. Aggour, and A. Toumi. "Review of savonius wind turbine design and performance." Energy Procedia 141 (2017): 383-388.

https://doi.org/10.1016/i.egypro.2017.11.047

[12] Tjahjana, Dominicus Danardono Dwi Prija, Syamsul Hadi, Yoga Arob Wicaksono, Diniar Mungil, Fahrudin Kurniawati, Ilham Satrio Utomo, and Sukmaji Indro Cahyono andAri Prasetyo. "Study on Performance Improvement of the Savonius Wind Turbine for Urban Power System with Omni-directional Guide Vane (ODGV)." Journal of Advanced Research in Fluid Mechanics and Thermal Sciences 55, no. 1 (2019) 126-135.

[13] Didane, Djamal Hissein, Nurhayati Rosly, Mohd Fadhli Zulkafli, and Syariful Syafiq Shamsudin. "Performance evaluation of a novel vertical axis wind turbine with coaxial contra-rotating concept." Renewable Energy 115 (2018): 353-361.

https://doi.org/10.1016/i.renene.2017.08.070

[14] Didane, Djamal Hissein, Nurhayati Rosly, Mohd Fadhli Zulkafli, and Syariful Syafiq Shamsudin. "Numerical investigation of a novel contra-rotating vertical axis wind turbine." Sustainable Energy Technologies and Assessments 31 (2019): 43-53.

https://doi.org/10.1016/j.seta.2018.11.006

[15] Didane, D. H., S. M. Maksud, M. F. Zulkafli, N. Rosly, S. S. Shamsudin, and A. Khalid. "Experimental Study on the Performance of a Savonius-Darrius Counter-Rotating Vertical Axis Wind Turbine." In IOP Conference Series: Earth and Environmental Science, vol. 268, no. 1, p. 012060. IOP Publishing, 2019. https://10.1088/1755-1315/268/1/012060

[16] Didane, Djamal Hissein, Siti Masyafikah Maksud, Mohd Fadhli Zulkafli, Nurhayati Rosly, Syariful Syafiq Shamsudin, and Amir Khalid. "Performance investigation of a small Savonius-Darrius counter-rotating vertical-axis wind turbine." International Journal of Energy Research (2019).

https://doi.org/10.1002/er.4874

[17] Mitulet, Lucia-Andreea, Gabriela Oprina, Rares-Andrei Chihaia, Sergiu Nicolaie, Adrian Nedelcu, and Mihail Popescu. "Wind tunnel testing for a new experimental model of counter-rotating wind turbine." Procedia Engineering 100 (2015): 1141-1149. https://doi.org/10.1016/i.proeng.2015.01.477

[18] D. Kudam. "Performance Evaluation of a Savonius Type Counter-Rotating Wind Turbine." Universiti Tun Hussein Onn Malaysia, 2018. 